\title{
Independence and Interdependence of Systems in District Heating
}

\author{
Jan van Deventer, Jonas Gustafsson, Jens Eliasson, Jerker Delsing, Henrik Mäkitaavola \\ Luleå University of Technology \\ S-97187 Luleå, Sweden
}

\begin{abstract}
In this paper, a fully operational wireless sensor and actuator network is presented. The network has the ability to control a district heating substation to ensure indoors comfort while minimizing energy waste by maximizing heat extraction from the distribution network. Introduced here is the foundation for a systems of systems approach within a district heating application, where several substations cooperate with the heat production plant. Presented are also the first steps to a service oriented architecture (SOA) where sensor nodes in the district heating network can cooperate with other nodes and systems, for example a ventilation control network.
\end{abstract}

\section{INTRODUCTION}

In our current era, it has become clear that we, as a society, must take care of our resources since they are not unlimited and their use can generate pollutions in various forms. In this paper, we present a wireless sensor network, initially developed to optimize a district heating substation, that eases the implementation of a system of systems within a district heating network. The proposed architecture additionally offers a service oriented architecture (SOA) that enables the introduction of new sensor nodes while letting the system reconfigure itself. SOA further opens for cooperative function between district heating system and other energy and comfort related system, e.g. ventilation, heat pumps, etc. This approach will both enable energy savings and quality of service for indoor comfort.

We begin the paper with a quick description of what district heating is. Subsequently is the presentation of a fully operational implementation of a wireless sensor and actuator network that optimizes the energy transfer to the building. We then discuss the independence of the system, that is the system must function on its own and handle local failure as far as possible. From an independent ability, we discuss the integration of a complete district heating distribution to form a systems of systems, where the systems are then also interdependent. Before concluding we consider an implementation of service oriented architecture of wireless sensor nodes and control systems.

\section{A. District heating}

District heating is an environment friendly and efficient method of heating buildings within an area. In other words, several buildings and quite often large portions of a city can have their space and water heated from a central heat plant. An analogy to this efficiency is public transportation where a bus is more efficient at transporting fifteen people than are

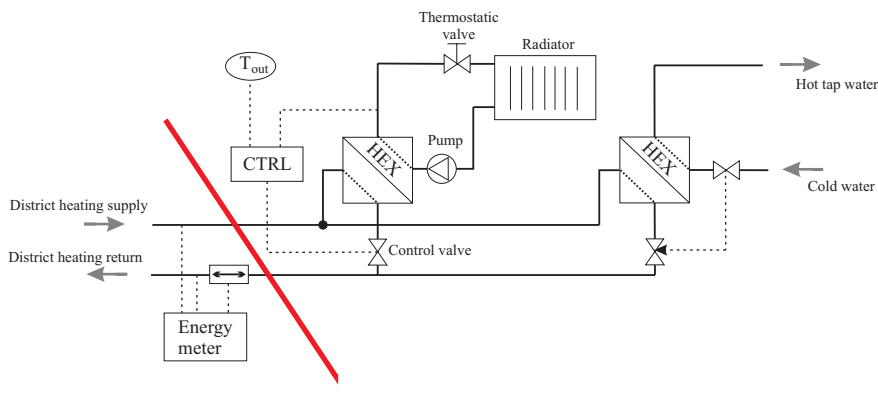

Fig. 1. Traditional control and communication architecture in a district heating substation. Please note the heat measurement at the primary side has no communication to the control at the secondary side (red line).

fourteen cars. The concept of district heating is quite appealing when the heat comes as the byproduct from an industrial process. When heat is produced in combination with electricity generation, district heating more than doubles the efficiency of the power plant [12].

In general, the heat from the plant is usually distributed under ground through a closed network of insulated pipes within which the heat is carried by water or steam. Water is prevalent in Europe while steam is more common in North America [11], [15]. The heat from the distribution network is transferred to the building through heat exchangers within a substitution where the space heating and domestic hot water are the secondary circuits (c.f. Fig. 1). There are various variations to the theme of energy distribution and transfer in district heating but the general description is sufficient here.

\section{B. Wireless Sensor and Actuator Networks}

This is the age of Information Technology; the Internet has been a dramatic catalyst providing information access to a worldwide population. In a similar fashion, suppling information within a district heating substation dramatically improves the performance of a substation, its quality of service, and offers new services to both the heat suppliers and their customers. For example, sharing information between the primary circuit, i.e. the distribution network, and the radiator circuit results in maximizing the heat extraction from the primary circuit since the control system now knows how much heat energy per volume is available to the substation at its location within the distribution network [9]. There are several other benefits such as reduced pumping through the distribution network and increased efficiency in the case of 


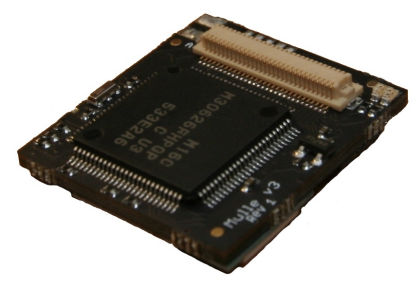

Fig. 2. A Mulle wireless sensor node.

combined heat and power plant [13].

Within the new architecture, each sensor and actuator is associated to a wireless node. We here describe these nodes, which are named Mulle [4], [10]. Their roles in the district heating substation are described in section II.

The Mulle platform is a small embedded system capable of communicating wirelessly with other nodes using TCP/IP over either Bluetooth or IEEE 802.15.4. As all embedded systems, it is able to measure and process a sensor's signal and/or request an action from an actuator.

The Mulle features a 16-bit Renesas M16C/62p microcontroller and a Bluetooth 2.0 module or a ZigBee compatible (IEEE 802.15.4) transceiver. It has an on-board $2 \mathrm{MB}$ flash memory, allowing storage of large amounts of sensor data, its configuration settings, and web page data and applications for the on-board web server. Flexibility as well as time driven operation are provided by a real-time clock, a temperature sensor, a battery monitor, LEDs and a high density expansion port. The latter is a 60-pin connector that enables connection to analog and digital I/O pins, power supply, and serial communication lines. The compact design occupies a total of $24 \times 26 \times 5 \mathrm{~mm}$. It is so small that none of the commercial components (heat meter, motorized valve and pump) had to be redesigned to be upgraded to hold a wireless sensor node.

Power utilization is an issue for the nodes that are not connected to the electrical network or associated to an actuator. The examples that arise several times in our system are the temperature sensors nodes. They must provide information for a very long duration, which ideally should be years. The current approach is to turn off the radio transceiver and put the micro-controller to sleep. The power usage in its lowest sleep mode is only $12 \mu \mathrm{W}$. The micro-controller wakes up every 15 minutes to measure the temperature. If there is a significant change in temperature, the radio module is momentarily turned on to communicate the information to the wireless network. By using this approach, a Mulle can operate for years even when equipped with relatively small batteries [6].

The Bluetooth software is designed in a modular fashion to allow adaptability to the system and its role of the node within the system. The Mulle can communicate with two of the worlds most widely spread technologies: TCP/IP and Bluetooth. The software uses the lwIP stack, and can communicate with several protocols including: IP, TCP, UDP, DHCP, NTP, and HTTP. The lwBT Bluetooth stack provides support for the following layers: HCI, L2CAP, SDP, BNEP, RFCOMM, and
PPP. The Bluetooth Profiles supported are: LAP, DUN, PAN, and SPP.

The use of TCP/IP and Bluetooth enables the Mulle to even utilize Bluetooth-equipped mobile phones as access points to reach the Internet although there is not a need for that in a district heating application. This allows a Mulle to transmit sensor data directly to users on the Internet without any specialized gateways. The advantage of using TCP/IP at the sensor or actuator level is the clear standardization of the Internet Protocol. This detail enables the infrastructure to be flexible to different sensor and actuator suppliers and opens the door to standardized service oriented architecture.

The Mulle with the IEEE 802.15.4 uses an operating system to handle all the different tasks in real time. Contiki [5] and TinyOS [3] are two well known operating systems used in research and commercial products. They are both designed with low-power embedded systems and wireless sensors in mind. Thus making them ideal to be used together with Mulle. Both Contiki and TinyOS also include IP stacks with 6LowPAN support [14]. 6LoWPAN is a acronym for IPv6 over Low power WPAN and is a standard that allows IPv6 packets to be sent over IEEE 802.15.4. Contiki utilizes the uIPv4 and uIPv6 written by Adam Dunkels, who also is the creator of Contiki. TinyOS uses BLIP, the Berkeley Low-power IP stack.

The nodes can communicate with each other or to an access point creating a wireless network. The next subsection describes the implementation of the wireless network.

\section{Wireless network}

The network used in this setup is a IP-based network with DHCP capabilities. The DHCP server is implemented in the Internet access point (c.f. Fig. 3), which is a Blackfin based embedded computer running $\mu$ Linux [1]. The new version of the access point used in this research communicates with Bluetooth, IEEE 802.15.4 with 6lowPAN, Wi-Fi and wired Ethernet. Its dimensions are 90x174 mm.

The control loop is today located in the Blackfin device, but could, in the future, be distributed between sensor nodes to improve control robustness. The network setup makes it possible to access all devices (Mulles) in the network from the Internet. This enables the system administrator to reconfigure and update the software on the nodes remotely.

\section{SUBSTATION CONTROL}

The current problem with commercially available substation is that their control systems today aim only towards comfort but do not optimize the performance of the substation in terms of energy efficiency. Their purpose is to guarantee that enough heat is delivered to the radiator circuit. This results in wasting heat energy that is available in the primary circuit. To optimize the system, additional information is needed by the controller but which is not currently available.

The traditional control and communication architecture is shown in Fig. 1. The heat energy measurement is located on the primary side of the substation. The controls of space heating and hot tap water delivery to the house are on the 


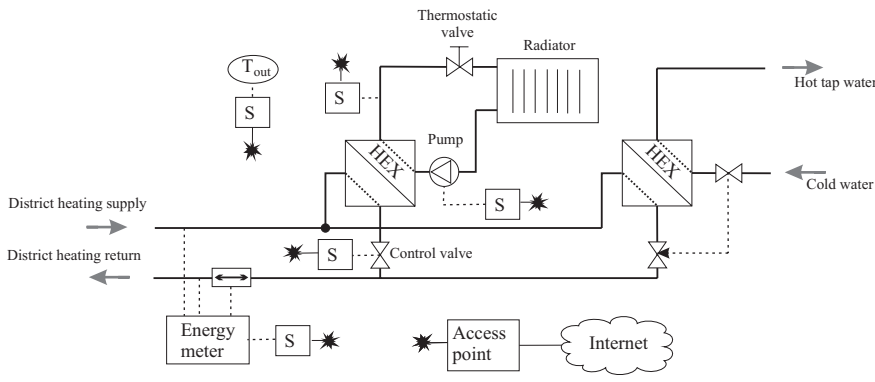

Fig. 3. New control and communication architecture in a district heating substation. Here all sensors, actuators and control devices regardless of location can exchange information.

secondary side of the substation, i.e. the radiator circuit and the domestic hot water circuit. These two functions, heat measurement and control, are independent and unaware of each other. For the space heating, there is a feedforward path which measures the outdoors temperature and regulates the flow of the primary circuit to achieve a specific temperature towards the radiators. The colder the outdoors temperature is, the hotter will be the temperature to the radiators. The feedback mechanism controlling the indoors temperature is the thermostatic valves located at each radiators. The flow through the radiator circuit is achieved with a fix speed pump.

With a wireless connection between sensors and actuators, the new infrastructure allows for the optimization as well as new diagnostics and services. In the hereby presented architecture, shown in Fig. 3, all sensors and actuators are enhanced with or replaced by sensor nodes which form the wireless sensor network based on TCP/IP.

This means that the barrier between the primary side with heat metering and the secondary side with heating and hot water control is effectively eliminated. This opens up for new measurement possibilities as discussed by Yliniemi [18] and new control strategies as discussed by Wollerstand et al. [17] and Gustafsson [8]. They take into account that the radiator circuit needs a certain time to heat up in the heat exchanger and a certain time to cool down in the radiators (i.e. heat transfer rates). By varying the flow rate of the radiator circuit, one can optimize the heat transfer in the heat exchanger and thereby minimize the flow through the primary circuit and in the radiator circuit. This requires that the pump has a continuously variable flow rate.

These new measurement and control strategies have substantial economical potentials. Very rough estimates shows savings of more than 1 million $€$ per year when increasing the primary temperature across the substation $(\Delta \mathrm{T})$ by $5^{\circ} \mathrm{C}$ in a $760 \mathrm{GWh}$ district heating system. Correlated with the financial savings are the environmental savings.

\section{QUALITY OF SERVICE}

The wireless sensor network could offer better diagnostics since it has access to much more information. Fig. 4 illustrates the case where there is a low water level in the radiator circuit. The pump has a pressure sensor and when the pressure is

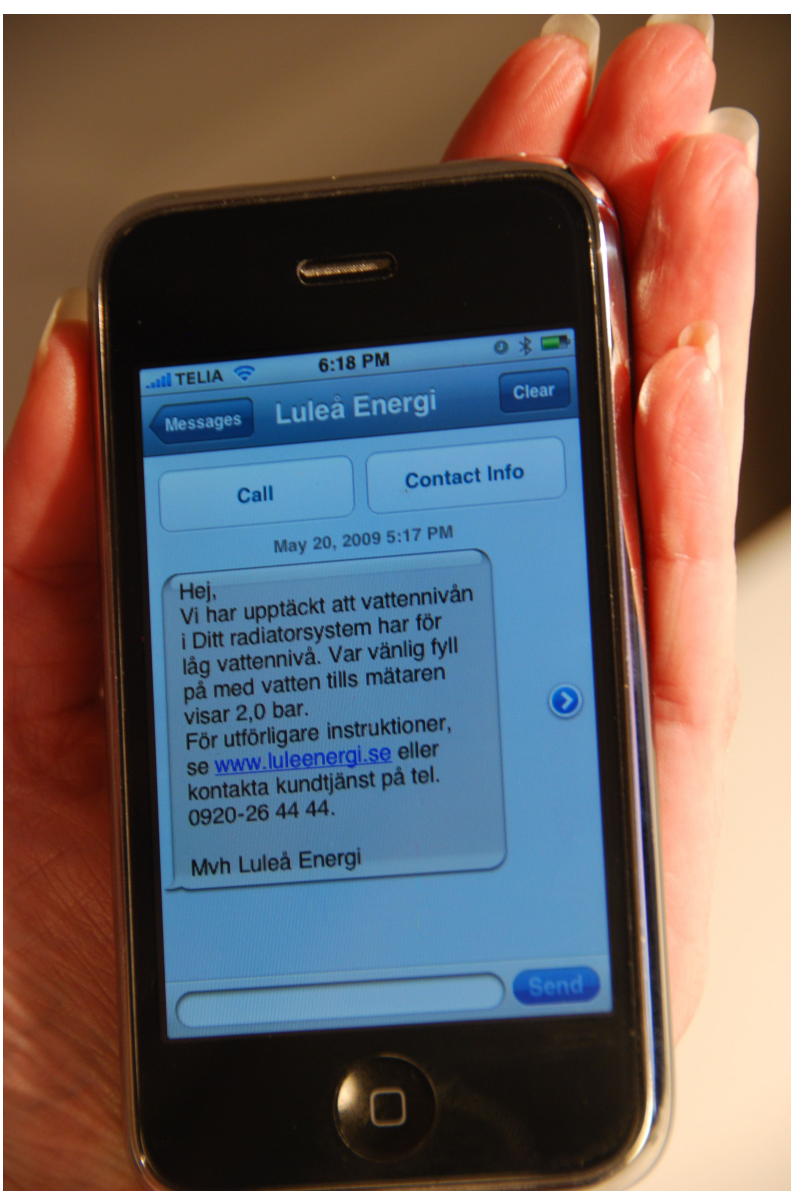

Fig. 4. Text message to a home owner that there is too little water in the radiator circuit with world wide web address to instructions on how to add water to it.

too low, the Mulle onboard the pump asks the heat provider to send an SMS or telephone text message to the end user to add water to the radiator circuit. Another example is an over dimensioned control valve which results in an on-off type control. The indoors comfort is achieved as the on-off behavior is filtered through the radiators but it creates pressure waves in the distribution network caused by this on-off type of control. The control system is aware of its control attempts and can only now communicate the problem to have a smaller valve installed.

The wireless network with its Internet connection offers new services such as energy separation which inform users how their total bill is divided between space and water heating [19]. This information influences end users' behavior because they can clearly see what their energy use is and its influence on the environment.

Quality of service is related to reliability of the components within the system. To address this, statistics of components are collected from which one can estimate the life of a standard component. To prevent system failure, components are replaced based on an estimated lifetime. However, statistics show only a trend but nothing about a specific installation. With the wireless sensor network, any malfunction in the 
substation is communicated immediately to the heat provider or home owner thereby detecting early faults or extending the in-use life of a component until it shows signs of aging. Additionally, statistics are automatically recorded on a server with not only failure rates but also in operation information.

\section{SySTEM OF SYSTEMS}

A demonstration substation is in operation with the wireless sensor network and information about its status is currently available to anybody with a web browser [2]. Direct access to the wireless network and its nodes is password protected such that it cannot be tampered with. From a heat supplier, information from each substation can offer vital information about the distribution network and service requests can help the network save further energy.

\section{A. Network information}

Each substation is able to provide information to the heat provider such as the primary supplied and returned temperatures as well as its through flow. This information assembled together from all the buildings in the district allows a real time overlay to a map of distribution area. One overlay of the map can paint the heat distribution over the network and the energy losses in the ground over the portrayed area. This overlay also informs about the differences between buildings. If, for example, a building has a lower supplied temperature, it can be that something is wrong with the temperature sensor or that the underground pipe supplying the building or its insulation is damaged. Another overlay can alternatively show the difference of temperature between the supplied and returned temperature to alert that a building's substation is inefficient or has a malfunction when that difference is too small or too large.

All these views over the district heating network enables a heat supplier to have a better control over its distribution network and address issues in a very short time.

The Swedish District Heating Association has also sponsored the development of a software program that analyzes data to allow a heat provider's energy use and its pollution contribution [13]. The data currently must be manually entered into the program. When using real time data, one can obtain the current and accumulated status of the financial and environmental cost of heating a whole district. This is related to the idea of energy separation mentioned in the previous section where the end user could for example see the carbon footprint of his or hers last shower.

The Swedish District Heating Association has in addition developed an online database to track the failure of components [7]. It requires that each heat provider has a technician to fill in details. With a deployed wireless sensor network, the information from each node is continuously collected in a database. Automatically analyzing this data will increase the quality of the statistics as likewise it considers functional components thereby allowing a correlation between failures and performance to be developed.

\section{B. Inter systems cooperation}

Having a communication to a central database operated by the heat provider allows for new cooperation between substations in a neighborhood but also between the heat plant and the customers to further reduce energy waste. We consider two examples here.

When a node or an access point within a substation needs information it does not have, it can request it from the central database. For instance, the outside temperature sensor node has stopped functioning. The node seeking the information notifies the maintenance department to have the node serviced and asks the database if it can get the value of the local outside temperature made available by one of the neighboring substations.

The second example addresses one of the current issues with district heating, which is the daily peaks of heat demand such as the one between 6:00 and 8:00 a.m. when an ample portion of the population takes a shower. If the heat is originally from an industrial process, it cannot be expected that the large excess heat comes from an increase in industrial production. One solution is to use one of the backip heat plants to be powered to intervene for the duration of the peak. However, to be able to turn on and off such a plant rapidly, fossil fuel or electricity are used. They are very expensive financially but also environmentally. In yet another project of the Swedish District Heating Association which is conducted in Karlshamn [16], it was shown that buildings which had stored heat in their structure (i.e. thermal capacity) could reduce their space heating energy consumption in a coordinated fashion to minimize the peak heat demand without affecting indoors comfort.

Therefore creating a system of systems in district heating is an obvious and natural progression to reduce energy usage while keeping end customers thermally conformable and improving quality of service.

\section{SERVICE ORIENTED ARCHITECTURE}

We here discuss two levels of services. The first is at the node level or within a system while the second one is at the level where systems interact with each other.

\section{A. Sensor nodes}

The Mulle sensor nodes are able to introduce themselves and the information services they offer using XML metadata. As an example, a temperature sensor can tell that it measures temperature in degree Celsius. When adding new nodes after the initial installation, the system must reconfigure itself without any nuisance. Two issues appear with this type of concept. The first one is the identity and location of the node while the second one has to do with the repository of application with those services.

For example, a temperature sensor node must know if it is located in the living room or in the kitchen. On the other hand the service client must be certain that the "living room temperature" node is in the same house. Trying to control the temperature in the neighbor's living room will prove to be 
quite a challenge. On the back side of the issue, people might want to keep the information of the their indoors temperature a private matter. In any of these scenarios, one solution is to have a service person from the heat provider involved either in the deployment or the sale of the node to pair it to the correct system. Another solution is to use the Mulle's ability to measure signal strength. During pairing to the network, the building owner should place the new node close to the access point, allowing the Mulle to be certain that physical proximity identifies the wireless network it is joining.

The expectation in service oriented architecture is that the client has a repository of procedures to handle different available services. This can prove to be difficult when we consider small wireless sensor nodes (limited memory) and in undefined applications. To illustrate this, consider the substation system has been built for controlling temperatures. When a humidity sensor node joins the wireless sensor network, how should the system use the new service? The proposed solution is for the substation nodes to ask the heat provider if they have in their repository an algorithm which handles humidity information. And if so, each concerned nodes would request to be remotely reprogrammed (a feature the Mulle already has). In other words, the repository is not located at the sensor node but on a server.

\section{B. Systems}

Services are not limited to nodes but can include other systems. The example to be addressed is ventilation. Large buildings (office buidings, schools, shopping malls) have advanced ventilation systems to keep a certain quality and comfort. These systems can waste energy when the outdoors temperature is cold and the buildings are not used such as early during the morning peak heat demand. To address this, it is vital for the different control systems to communicate and exchange information. If a ventilation system is upgraded to have a wireless sensor network, it can present its services to the heating system which then will turn to the remote repository to learn how to cooperate.

\section{CONCLUSION}

A wireless sensor network in a district heating substation can optimize the heat extraction from the distribution network while it guaranties indoors comfort and quality of service. It is an independent system that function by itself. Within the district heating network, when several building have a deployed wireless sensor networks in their substations, they can form an interdependent set of systems that cooperate by sharing information and support each other. When the heat plant join into the system of systems, the peak loads can be flattened out. All this results in saving natural resources and reducing cost or increasing benefits.

The wireless sensor network offers additionally a service oriented architecture, which at the system level means that two different systems can cooperate together although they initially did not know how to. The example described in the paper is ventilation of large buildings like offices and schools.
Using a wireless sensor network with nodes that communicate with TCP/IP simplifies implementation of a system of systems and the use of 6LoWPAN provide system transparency over the Internet.

\section{ACKNOWLEDGMENT}

The authors would like to thank the Swedish District Heating Association for funding the research through Fjärrsyn.

\section{REFERENCES}

[1] Analog devices, blackfin processors. http://www.analog.com/en/ embedded-processing-dsp/blackfin/content/index.html, January 2009.

[2] Mulle-based district heating subsystem monitoring. http://sm-pc777.sm. ltu.se/ jens/district_heating/, October 2009.

[3] February 2010.

[4] Eistec ab. http://www.eistec.se/, February 2010.

[5] Adam Dunkels. The contiki operating system. http://www.sics.se/ contiki/, February 2010.

[6] Jens Eliasson, Per Lindgren, and Jerker Delsing. A Bluetooth-based Sensor Node for Low-Power Ad Hoc Networks. Journal of Computers (JCP), pages 1-10, May 2008.

[7] Svensk Fjärrvärme. District heating component statistics. http://statistik. svenskfjarrvarme.se/, November 2009.

[8] Jonas Gustafsson. Distributed wireless control strategies for district heating substations. Licentiate thesis,, Luleå University of Technology, Luleå, Sweden, 2009.

[9] Jonas Gustafsson, Jerker Delsing, and Jan van Deventer. Improved district heating substation efficiency with a new control strategy. Applied Energy, doi:10.1016/j.apenergy.2009.12.015, 2010.

[10] Jonny Johansson, Matthias Völker, Jens Eliasson, Åke Östmark, Per Lindgren, and Jerker Delsing. MULLE:a minimal sensor networking device - implementation and manufacturing challenges. In Proc. IMAPS Nordic 2004. IMAPS, 2004.

[11] Committee on District Heating and National Research Council Cooling. District Heating and Cooling in the United States: District Heating and Cooling in the United States: Prospects and Issues. The National Academies Press, Washington DC, 1985.

[12] Marc A. Rosen, Minh N. Le, and Ibrahim Dincer. Efficiency analysis of a cogeneration and district energy system. Applied Thermal Engineering, 25(doi:10.1016/j.applthermaleng.2004.05.008):147-159, 2005.

[13] Patrik Selinder. Värderingsmetod lava 2. Technical report, Svensk Fjärrvärme, 2010 (to be published).

[14] Zach Shelby and Carsten Bormann. 6LoWPAN: The Wireless Embedded Internet. Willey, November 2009.

[15] Bard Skagestad and Peter Mildenstein. District heating and cooling connection handbook. Technical report, International Energy Agency, 2002.

[16] Fredrik Wernstedt, Christian Johansson, and Janusz Wollerstrand Sänkning av returtemperaturer genom laststyrning. Report 2008:2, ISBN 978-91-7381-007-4, Svensk Fjärrvärme, 2008.

[17] Janusz Wollerstrand, Patric Ljunggren, and Per-Olof Johansson. Optimal reglering av radiatorsystem. Fjärrsyn Rapport 2007:6, Svensk Fjärrvärme, Stockholm, Sweden, 2007.

[18] Kimmo Yliniemi. Fault detection in district heating substations. Licentiate Thesis, ISSN 2005:60, Luleå University of Technology, Luleå, Sweden, 2005.

[19] Kimmo Yliniemi, Jerker Delsing, and Jan van Deventer. Experimental verification of a method for estimating energy for domestic hot water production in a 2-stage district heating substation. Energy and Buildings, 41:169-174, 2009. 


\section{IEEE COPYRIGHT AND CONSENT FORM}

To ensure uniformity of treatment among all contributors, other forms may not be substituted for this form, nor may any wording of the form be changed. This form is intended for original material submitted to the IEEE and must accompany any such material in order to be published by the IEEE.Please read the form carefully and keep a copy for your files.

TITLE OF PAPER/ARTICLE/REPORT, INCLUDING ALL CONTENT IN ANY FORM, FORMAT, OR MEDIA (hereinafter, "The Work"):Independence and Interdependence of Systems in District Heating

\section{COMPLETE LIST OF AUTHORS:Jan van Deventer and Jonas Gustafsson and Jens Eliasson and Jerker Delsing and Henrik Makitaavola}

IEEE PUBLICATION TITLE (Journal, Magazine, Conference, Book):2010 IEEE International Systems Conference (IEEE SysCon 2010)

\section{COPYRIGHT TRANSFER}

1. The undersigned hereby assigns to The Institute of Electrical and Electronics Engineers, Incorporated (the IEEE) all rights under copyright that may exist in and to: (a) the above Work, including any revised or expanded derivative works submitted to the IEEE by the undersigned based on the Work; and (b) any associated written or multimedia components or other enhancements accompanying the Work.

\section{See Retained Rights ,below.}

\section{CONSENT AND RELEASE}

2. In the event the undersigned makes a presentation based upon the Work at a conference hosted or sponsored in whole or in part by the IEEE, the undersigned, in consideration for his/her participation in the conference, hereby grants the IEEE the unlimited, worldwide, irrevocable permission to use, distribute, publish, license, exhibit, record, digitize, broadcast, reproduce and archive, in any format or medium, whether now known or hereafter developed: (a) his/her presentation and comments at the conference; (b) any written materials or multimedia files used in connection with his/her presentation; and (c) any recorded interviews of him/her (collectively, the Presentation). The permission granted includes the transcription and reproduction of the Presentation for inclusion in products sold or distributed by IEEE and live or recorded broadcast of the Presentation during or after the conference.

3. In connection with the permission granted in Section 2, the undersigned hereby grants IEEE the unlimited, worldwide, irrevocable right to use his/her name, picture, likeness, voice and biographical information as part of the advertisement, distribution and sale of products incorporating the Work or Presentation, and releases IEEE from any claim based on right of privacy or publicity.

4. The undersigned hereby warrants that the Work and Presentation (collectively, the Materials) are original and that he/she is the author of the Materials. To the extent the Materials incorporate text passages, figures, data or other material from the works of others, the undersigned has obtained any necessary permissions. Where necessary, the undersigned has obtained all third party permissions and consents to grant the license above and has provided copies of such permissions and consents to IEEE.

[ ] Please check this box if you do not wish to have video/audio recordings made of your conference presentation.

\section{AUTHOR RESPONSIBILITIES}

The IEEE distributes its technical publications throughout the world and wants to ensure that the material submitted to its publications is properly available to the readership of those publications. Authors must ensure that their Work meets the requirements as stated in section 8.2.1 of the IEEE PSPB Operations Manual, including provisions covering originality, authorship, author responsibilities and author misconduct. More information on IEEE's publishing policies may be found at http://www.ieee.org/web/publications/pubtoolsandpolicyinfo/index.html. Authors are advised especially of IEEE PSPB Operations Manual section 8.2.1.B12: "It is the responsibility of the authors, not the IEEE, to determine whether disclosure of their material requires the prior consent of other parties and, if so, to obtain it." Authors are also advised of IEEE PSPB Operations Manual section 8.1.1B: "Statements and opinions given in work published by the IEEE are the expression of the authors." 


\section{RETAINED RIGHTS/TERMS AND CONDITIONS}

1. Authors/employers retain all proprietary rights in any process, procedure, or article of manufacture described in the Work.

2. Authors/employers may reproduce or authorize others to reproduce The Work, material extracted verbatim from the Work, or derivative works to the extent permissible under United States law for works authored by U.S. Government employees, and for the author's personal use or for company or organizational use, provided that the source and any IEEE copyright notice are indicated, the copies are not used in any way that implies IEEE endorsement of a product or service of any employer, and the copies themselves are not offered for sale.

3. Authors/employers may make limited distribution of all or portions of the Work prior to publication if they inform the IEEE in advance of the nature and extent of such limited distribution.

4. In the case of a Work performed under a U.S. Government contract or grant, the IEEE recognizes that the U.S. Government has royalty-free permission to reproduce all or portions of the Work, and to authorize others to do so, for official U.S. Government purposes only, if the contract/grant so requires.

5. For all uses not covered by items 2, 3, and 4, authors/employers must request permission from the IEEE Intellectual Property Rights office to reproduce or authorize the reproduction of the Work or material extracted verbatim from the Work, including figures and tables.

6. Although authors are permitted to re-use all or portions of the Work in other works, this does not include granting third-party requests for reprinting, republishing, or other types of re-use. The IEEE Intellectual Property Rights office must handle all such third-party requests.

\section{IEEE Copyright Ownership}

\section{INFORMATION FOR AUTHORS}

It is the formal policy of the IEEE to own the copyrights to all copyrightable material in its technical publications and to the individual contributions contained therein, in order to protect the interests of the IEEE, its authors and their employers, and, at the same time, to facilitate the appropriate re-use of this material by others. The IEEE distributes its technical publications throughout the world and does so by various means such as hard copy, microfiche, microfilm, and electronic media. It also abstracts and may translate its publications, and articles contained therein, for inclusion in various compendiums, collective works, databases and similar publications.

\section{Author/Employer Rights}

If you are employed and prepared the Work on a subject within the scope of your employment, the copyright in the Work belongs to your employer as a work-for-hire. In that case, the IEEE assumes that when you sign this Form, you are authorized to do so by your employer and that your employer has consented to the transfer of copyright, to the representation and warranty of publication rights, and to all other terms and conditions of this Form. If such authorization and consent has not been given to you, an authorized representative of your employer should sign this Form as the Author.

\section{$\underline{\text { Reprint/Republication Policy }}$}

The IEEE requires that the consent of the first-named author and employer be sought as a condition to granting reprint or republication rights to others or for permitting use of a Work for promotion or marketing purposes.

\section{GENERAL TERMS}

1. The undersigned represents that he/she has the power and authority to make and execute this assignment.

2. The undersigned agrees to indemnify and hold harmless the IEEE from any damage or expense that may arise in the event of a breach of any of the warranties set forth above.

3. In the event the above work is not accepted and published by the IEEE or is withdrawn by the author(s) before acceptance by the IEEE, the foregoing copyright transfer shall become null and void and all materials embodying the Work submitted to the IEEE will be destroyed.

4. For jointly authored Works, all joint authors should sign, or one of the authors should sign as authorized agent for the others. 
THIS FORM MUST ACCOMPANY THE SUBMISSION OF THE AUTHOR'S MANUSCRIPT.

Questions about the submission of the form or manuscript must be sent to the publication's editor.

Please direct all questions about IEEE copyright policy to:

IEEE Intellectual Property Rights Office, copyrights@ieee.org, +1-732-562-3966 (telephone) 